\title{
Article
}

\section{Evidence for selective executive function deficits in ecstasy/polydrug users}

Fisk, John and Montgomery, C.

Available at http://clok.uclan.ac.uk/1191/

Fisk, John ORCID: 0000-0002-2981-0870 and Montgomery, C. (2009) Evidence for selective executive function deficits in ecstasy/polydrug users. Journal of Psychopharmacology, 23 (1). pp. 40-50. ISSN 0269-8811

It is advisable to refer to the publisher's version if you intend to cite from the work. http://dx.doi.org/10.1177/0269881108089815

For more information about UCLan's research in this area go to http://www.uclan.ac.uk/researchgroups/ and search for < name of research Group>.

For information about Research generally at UCLan please go to http://www.uclan.ac.uk/research/

All outputs in CLoK are protected by Intellectual Property Rights law, including Copyright law. Copyright, IPR and Moral Rights for the works on this site are retained by the individual authors and/or other copyright owners. Terms and conditions for use of this material are defined in the policies page.

\section{CLoK}

Central Lancashire online Knowledge www.clok.uclan.ac.uk

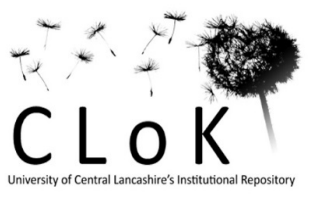


Evidence for selective executive function deficits in ecstasy/polydrug users.

\author{
John E. Fisk, PhD \\ University of Central Lancashire, \\ Catharine Montgomery, $\mathrm{PhD}$ \\ Liverpool John Moores University
}

Running head: selective executive function deficits

Corresponding author:

Dr John E Fisk

Department of Psychology

University of Central Lancashire

Preston PR1 2HE

United Kingdom

Tel 44 (0) 1772894465

Fax $44(0) 1772892925$

e-mail: jfisk@uclan.ac.uk 
John E Fisk

\section{$\underline{\text { Abstract }}$}

Previous research has suggested that the separate aspects of executive functioning are differentially affected by ecstasy use. While the inhibition component executive process appears to be unaffected by ecstasy use, it is unclear whether this is true of heavy users under conditions of high demand. Tasks loading on the updating component executive process have been shown to be adversely affected by ecstasy use. However, it remains unclear whether the deficits observed reflect the executive aspects of the tasks and whether they are domain general in nature affecting both verbal and visuo-spatial updating. Fourteen heavy ecstasy users, 39 light ecstasy users and 28 non users were tested on tasks loading on the inhibition executive process (random letter generation) and the updating component process (letter updating, visuo-spatial updating and computation span). Heavy users were not impaired in random letter generation even under conditions of high demand. Ecstasy related deficits were observed on all updating tasks. These deficits remained statistically significant following controls for various aspects of cannabis use. It was concluded that the inhibition component executive process is unaffected by ecstasy use even among heavy users. By way of contrast, the updating component process appears to be impaired in ecstasy users with the deficit apparently domain general in nature.

Keywords: ecstasy (MDMA), inhibition, updating, executive, random generation, visuo-spatial. 
There is cause to believe that among the many illicit drugs commonly in use, ecstasy in particular causes long term impairment to cognitive processes through its effects on the serotonin system (Gouzoulis-Mayfrank \& Daumann 2006; Morgan, 2000; Reneman et al 2006). Morgan (2000, page 234) has noted that 'it has been proposed that it [serotonin] may play an orchestrating role in cognition'. More specifically, the serotonin system is believed to underpin working memory processes through its modulation of the dopaminergic systems that support prefrontal executive processes (Luciana, Collins, \& Depue, 1998; Robbins 2000).

Recent investigations of executive functioning suggest that the central executive is fractionated. For example, Miyake et al. (2000) studied the separability of three supposed executive functions: mental set shifting ("shifting”), information updating and monitoring (“updating”), and inhibition of pre-potent responses (“inhibition”). Structural equation modelling revealed that the three executive functions were clearly separate and appeared to contribute differentially to performance on higher level tasks that are known to be reliant on prefrontal cortical resources. For example, the Wisconsin Cart Sort Task (WCST) was linked to the shifting component, the Tower of Hanoi to the inhibition component, random number generation to both the inhibition and updating components, and operation span to the updating component.

Using factor analysis, Fisk and Sharp (2004) provided further support for Miyake et al's model, finding that reading span and computation span (analogous to Miyake et al's operation span task), letter updating (Morris \& Jones, 1990) and a visuo-spatial serial recall task (Brooks, 1967) all loaded on a single factor corresponding to Miyake et al’s updating executive process. Aspects of random letter generation loaded on a separate 
factor corresponding to Miyake et al's inhibition executive process, while WCST measures loaded on a third factor (equivalent to Miyake et al's switching executive process). Additionally, a fourth factor emerged which Fisk and Sharp termed access to long-term memory and on which verbal fluency tasks loaded.

Previous research from our laboratory (Fisk et al, 2004; Montgomery et al, 2005; Wareing et al 2004) utilising Miyake et al's conceptual framework, revealed ecstasyrelated deficits in memory updating (computation span and letter updating), and access to long-term memory (verbal fluency). No differences were observed on tasks assessing the switching (the plus-minus and number letter task) and inhibition (random letter generation) component processes. However inconsistencies in this area of research have emerged. From our own laboratory, while Wareing, et al (2000) found ecstasy users to be impaired in random letter generation, we have failed to obtain this outcome in subsequent studies (Fisk, et al, 2004; Montgomery, et al, 2005). Similarly the ecstasy-related deficits in relation to the updating executive component process that emerged from our own research (Montgomery et al, 2005) have not have been replicated by Dafters (2005) using the keeping track task.

Clearly these inconsistencies require explanation and warrant further research. Wareing et al's (2000) participants had an atypically high estimated lifetime ecstasy dose exceeding 1000 tablets and the random letter generation task used, restricted participants to producing only consonants. In our later study (Fisk et al, 2004) those we tested had an appreciably lower lifetime exposure to the drug and we administered the original version of the task (Baddeley 1966) in which any letter of the alphabet may be produced. It is possible therefore that ecstasy might impair the inhibition component process but only at 
high does and only when the processing load is substantial. To resolve this ambiguity, it would be desirable to repeat the consonants only random generation task on a group of high dosage users in order to replicate our previous findings.

Questions have also emerged concerning our previous results which demonstrated ecstasy-related updating component executive deficits. First at six letters, the maintenance element of the updating task exceeded the letter span of the majority of participants that we tested. Consequently many participants may have adopted a free recall recency based strategy negating the need for updating (Collette et al, 2006; SmithSpark et al, 2003). It would be desirable to repeat our original experiment ensuring that the maintenance component of the task does not exceed the letter span of our participants. Second, we have recently demonstrated ecstasy-related deficits in visuo-spatial working memory tasks (Wareing et al, 2004; 2005) although it is unclear which executive component processes may be implicated in this regard. Recent conceptualisations of executive function tasks suggest the processing component of these is domain general (e.g., Bayliss et al 2003; Kane et al , 2004). If the updating component does reflect some domain general process it would be expected that the impairments that we have observed in verbal updating would also manifested in visuo-spatial updating .

\section{Method}

\section{Design and Analysis.}

For the random letter generation task, a mixed design was used with rate of letter generation (with three levels; 4 seconds, 2 seconds, and 1 second)) within participants 
and ecstasy users group (with three levels; heavy, light, and nonuser) between participants. Dependent variables were the number of alphabetically ordered pairs, number of repeated pairs, redundancy, and the number of vowel intrusions. With regard to the updating executive component tasks, verbal and spatial updating, and the computation span task, a multivariate design was used with user group (3 levels) between participants and the three measures of executive functioning as dependent variables. Orthogonal contrasts were employed in which heavy ecstasy users were compared to light users and the two ecstasy user groups combined compared with nonusers. Orthogonal contrasts were used as they allow inter-group comparisons to be made while controlling the Type 1 error rate without the need to adjust the alpha level per comparison (Tabachnick \& Fidell, 2001).

\section{Participants.}

Fourteen heavy ecstasy users (mean age 22.86; 9 male), 39 light ecstasy users (mean age 21.41; 19 male) and 28 non-user controls (mean age 20.71; 7 male) took part in the study. The heavy users group comprised all of those users with an estimated lifetime dose exceeding 400 tablets, (mean 1000.21, s.d., 786.41). Light users were those with an estimated lifetime dose of less than 400 tablets, (mean 149.69, s.d., 96.91). The cut off point of four hundred tablets was determined by trial and error so as to produce a high use group with a mean lifetime dose of 1000 tablets as this was the level of exposure characterising the ecstasy users in our previous study (Wareing et al 2000). Nonusers were those who indicated that they had never used ecstasy. Participants were recruited via direct approach to university students, and the snowball technique (Solowij et al, 1992). With 14 ecstasy users, the present sample is sufficient to detect a difference of 1.25 for $\alpha$ 
$=.05$ and $\beta=.20$ (Hinkle et al, 1994). Participants were requested to refrain from ecstasy use for at least 7 days and ideally 10 days prior to testing. The mean period of abstinence was actually 22 and 27 weeks for heavy users and light users respectively; median abstinence period 5.5 and 4 weeks respectively. Participants were also requested not to use any other illicit drugs for at least 24 hours and ideally for 7 days prior to testing.

\section{Measures.}

Patterns of drug use and other relevant lifestyle variables were investigated via means of a background questionnaire. The questionnaire gauged the use of ecstasy and other drugs, as well as age, years of education, general health and other relevant lifestyle variables. In relation to other drugs, participants were asked a range of questions including frequency and duration of use and the last time that they had used each drug. Participants were also questioned concerning their history of drug use, and using a technique employed by Montgomery, et al (2005), these data were used to estimate total lifetime use for each drug. Average weekly dose and the amount of each drug consumed within the previous 30 days were also assessed. Fluid intelligence was measured via Raven’s Progressive Matrices (Raven et al, 1998), and premorbid intelligence was assessed via the National Adult Reading Test (NART, Nelson, 1982).

Letter Span: Consonants were presented sequentially on a computer screen for 1.25 seconds. Participants were then required to recall the letters in the order in which they were presented. The task commences with three sets of two letters, and is then increased to three sets of three, four, five etc., until the individual fails on at least two out of three trials. Digit span was administered in a similar manner except that the letters were replaced with digits. 
Updating. Updating has been used extensively as a measure of prefrontal executive functioning. (see for example, Fisk \& Sharp, 2003; 2004; Miyake et al, 2000; Morris \& Jones, 1990; Smith-Spark \& Fisk, in press; van der Linden et al 1999). The participant’s letter span, 'n', was determined. In the consonant updating task the participant was presented with a random sequence of between $n$ and $n+6$ consonants on a computer screen. Twenty-four such lists were presented, and in each case, the participant was unaware of the number of consonants to be presented. The task was always to recall the most recent ' $n$ ' consonants in the order in which they were presented. (Thus the maintenance element of the task was limited to the individual's actual span. This contrasts favourably with our previous study where at six letters the maintenance requirement exceeded the span of most of our participants.) The participant experienced six trials at each of the four list lengths: $n, n+2, n+4$, and $n+6$ items. The order in which the lists were presented was randomised. A single composite score of updating was calculated by computing the average number correct for each serial position over the 6 trials at each list length. The resulting figures were then averaged over list length and serial position.

The spatial updating task was analogous to consonant updating except that it involved the serial recall of cells that were highlighted sequentially, one at a time, in a Corsi style display. The participant's spatial span, 'n', was determined. In the updating task the participant was presented with a random sequence of between $n$ and $n+6$ cells highlighted on a computer screen in a Corsi style configuration. Twenty-four such sequences were presented, and in each case, the participant was unaware of the number of cells that were highlighted. The task was always to recall the most recent ' $n$ ' cells in the 
order in which they were presented. As in the consonant task, the participant experienced six trials at each of the sequence lengths. The order in which the lists were presented was randomised. A single composite score of updating was calculated using the same procedure as outlined for the consonant updating task.

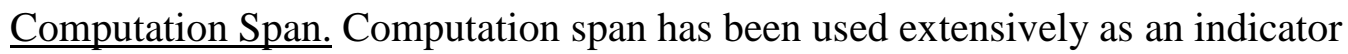
of working memory functioning in the cognitive ageing literature (Fisk \& Warr, 1996; Salthouse \& Babcock, 1991) and it is similar to the operation span measure used by Miyake, et al (2000) in their investigation of executive processes. Participants were required to solve a number of arithmetic problems (e.g., 4+7 = ?) by circling one of three multiple-choice answers as each problem was presented. They were also required to simultaneously remember the second digit of each presented problem. At the end of each set of problems the second digits had to be recalled in the order in which they were presented. The number of arithmetic problems that the participant had to solve, while at the same time remembering each second digit, gradually increased as the test proceeded. For each of the first three trials only a single problem was presented. For the next three trials, two problems were presented. Subsequently, the number of problems presented per trial increased by one every third trial. In order to proceed, the participant was required to be correct in at least two of the three trials at the current level. Computation span was defined as the maximum number of end digits recalled in serial order, with the added requirement that the corresponding arithmetic problems had been solved correctly. In order to take account of individual differences in the non-executive maintenance component of the task, the load on executive resources was computed as the percentage 
difference between the computation and digit span scores. Large percentage differences are indicative of poor executive functioning.

Random letter generation. A computer display and concurrent auditory signal was used to pace responses. Participants were asked to speak aloud a letter every time the signal was presented. They were told to produce only consonants (i.e., to avoid the letters a, e, i, o, and u); to avoid repeating the same sequence of letters; to avoid producing alphabetically ordered sequences; and to try to speak each letter with the same overall frequency. Individuals attempted to produce three sets of 100 letters; one set at a rate of one letter every $4 \mathrm{~s}$, a second set at one letter every $2 \mathrm{~s}$, and a third at one letter every $1 \mathrm{~s}$. The order in which the sets were generated was randomised. The experimenter recorded the responses on an answer sheet. The test yields four scores. First, the number of alphabetically ordered pairs; second, a repeat sequences score corresponding to the number of times that the same letter pair is repeated; third, a "redundancy" score, which measures the extent to which all 26 letters of the alphabet are produced equally often ( $0 \%$ being truly random); and fourth, the number of vowel intrusions. In all cases, higher scores are indicative of poor performance.

\section{Procedure.}

Participants were informed of the general purpose of the experiment, and written informed consent was obtained. The tests were administered under laboratory conditions, and a computer running MS-DOS was used for the computer based tasks. The tests were administered in the following order: background questionnaire, random letter generation, digit, letter, and spatial span, computation span, letter and spatial updating, Raven's progressive matrices, and the NART. Participants were fully debriefed, paid $£ 15$ in store 
John E Fisk

vouchers, and given drugs education leaflets. The study was approved by the Ethics Committee of Liverpool John Moores University, and was administered in accordance with the Declaration of Helsinki.

$\underline{\text { Results }}$

There were no significant differences between the groups on the Raven’s and NART measures and the number of years of education. Inspection of Table 1 reveals that age differed significantly between the groups. Tukey's test revealed that heavy users were significantly older than the other two groups, $\mathrm{p}<.01$ and $\mathrm{p}<.05$ in relation to nonusers and light users respectively. Light users and nonusers did not differ significantly from each other. Table 1 also contains mean simple span scores (digit, letter and spatial) for each of the three groups. Ecstasy users were unimpaired on these measures in fact scoring marginally higher compared to non ecstasy users.

$<$ Insert Table 1 about here>

The vast majority of all of the groups had previous exposure to cannabis. Ninetythree percent of heavy ecstasy users, $87 \%$ of light users and $75 \%$ of non ecstasy users indicated that they had used cannabis. Cocaine use was also common among ecstasy users. All heavy ecstasy users and 72\% of light ecstasy users indicated that they had previously used cocaine. However, only $11 \%$ of nonusers had had any exposure to this drug. Other drugs that had been previously used included amphetamine and LSD but use of these was less prevalent and limited to the ecstasy user groups. Sixty-four percent of heavy ecstasy users and 33\% of light ecstasy users indicated that they had previously used amphetamine. The equivalent figures for LSD were respectively, $64 \%$ and $13 \%$. For 
those drugs where it was possible to quantify the level of use a number of relevant measures are set out in Table 2. Heavy ecstasy users also consumed substantial quantities of cocaine and cannabis. Light ecstasy users also used these drugs but to a lesser extent. Among non ecstasy users the only illicit drug that was used was cannabis but the exposure to this drug was of a lower order compared to the other two groups. (Three non ecstasy users indicated that they had used cocaine on one or two previous occasions but were unable to quantify the amount.) For the most part the measures of drug use were not normally distributed. In many instances the median response was zero and more generally the distributions were positively skewed. In addition the group variances were generally heterogeneous. As a consequence nonparametric analyses were used with the results revealing that most of the indicators of drug use set out in Table 2 differed significantly between the groups. With regard to differences between the two ecstasy user groups, heavy users scored significantly higher than light users in terms of total lifetime and average weekly consumption of both cannabis and cocaine. Heavy users had used ecstasy and cocaine significantly longer than light users although length of cannabis user did not differ significantly between the two ecstasy user groups. Also there were no significant differences between heavy and light ecstasy users in terms of their use of illicit drugs in the previous 10 and 30 days.

$<$ Insert Table 2 about here $>$

Outcomes for the different aspects of executive functioning are set out in Table 3. In all aspects of random letter generation the scores were similar between the groups. Mixed ANOVA was used with group between participants and rate of letter generation within. Consistent with the trends evident in the means, none of the group effects were 
statistically significant, for each of the four analyses (redundancy, repeat sequences, alphabetical sequences and vowel intrusions), $\mathrm{F}<1$. Also in each case the interaction between group and rate of letter generation was non significant, again in each of the four analyses, $\mathrm{F}<1$. The number of letters produced was close to ceiling (i.e., 100 letters) for all groups at the four and two second generation rates. Although performance declined at the one second rate this was equally apparent for all groups. The maximal number of letters generated by most participants at the four and two second rates prevents meaningful analysis. However, ANOVA with group between participants and the number of letters generated at the one second rate as the dependent variable revealed no significant difference between the groups, $\mathrm{F}<1$. Thus to summarise the present results provide no evidence of ecstasy-related differences in the inhibition component executive process on which random letter generation is known to load.

$<$ Insert Table 3 about here $>$

The percentage reduction in capacity associated with the concurrent processing component of the computation span task is set out in Table 3 along with the outcomes for the spatial and verbal (consonant) updating tasks. All three measures are believed to load on the updating executive component process. For each of these three indicators of executive functioning non ecstasy users outperform both ecstasy user groups. Non users exhibit substantially lower costs in relation to the processing component of the computation span task. They also exhibit more efficient updating both in relation to verbal and visuo-spatial stimuli. MANOVA with user group between participants and the three measures of the updating component executive process as dependent variables revealed a significant multivariate group effect, Wilks’ lambda $=.836, \mathrm{~F}(6,150)=2.34$, 
John E Fisk

$\mathrm{p}<.05$. Regarding the univariate outcomes, the group differences were statistically significant for both computation span and spatial updating, with F values of 3.23 and 3.97 respectively on 2,77 degrees of freedom, $\mathrm{p}<.05$ in both cases. The group difference for the verbal updating task failed to reach significance, $F(2,77)=2.23, \mathrm{p}>.05$. Difference contrasts revealed that nonusers performed significantly better than the combined user groups on the computation span and spatial updating measures, $\mathrm{p}<.05$ and $\mathrm{p}<.01$ respectively, the difference approached significance for the verbal updating task, $p=.091$. However, the contrasts revealed that the two user groups did not differ from each other on any of the updating measures, $\mathrm{p}>.05$ in all cases.

As inspection of Table 2 revealed, ecstasy users (especially heavy users) consumed considerably more cannabis compared to non ecstasy users both in terms of long term and recent use. It is possible therefore that various aspects of cannabis use may have accounted for the ecstasy-related group differences that were obtained on the updating executive component measures. To control for this possibility, the MANOVA was repeated with the two long term (total lifetime consumption and average weekly consumption) and two short term measures of cannabis use (amount used in the last 10 and 30 days) as covariates. The multivariate group effect remained significant, Wilks’ lambda $=.793, \mathrm{~F}(6,118)=2.42, \mathrm{p}<.05$. Regarding the univariate outcomes, the group differences were statistically significant for verbal updating and spatial updating with $\mathrm{F}$ values of 3.86 and 3.62 respectively on 2,61 degrees of freedom, $\mathrm{p}<.05$ in both cases. The group difference for the computation task approached significance, $\mathrm{F}(2,61)=3.02$, $\mathrm{p}=.056$. Difference contrasts revealed that nonusers performed significantly better than the combined user groups on all three measures, $\mathrm{p}<.05$ in all cases, while the two user 
groups did not differ significantly from each other on any of the measures, $\mathrm{p}>.05$ in all cases. Tests for homogeneity of regression were conducted for each covariate with respect to each of the dependent variables yielding a total of 12 analyses. In 11 of the 12 cases, homogeneity of regression was obtained, $\mathrm{p}>.05$, for the covariate by group interaction in all cases. In one case homogeneity of regression was not obtained. This was in relation to average weekly cannabis consumption and the computation span measure where the covariate by group interaction yielded $\mathrm{F}(2,62)=4.81, \mathrm{p}<.05$.

The absence of cocaine users among the non-ecstasy users makes it impossible to control statistically for the potentially confounding effects of cocaine use since it is not possible to test for homogeneity of regression. To evaluate the extent to which cocaine use (as well as ecstasy and cannabis use) is associated with performance on the updating executive component measures we examined the correlations (Spearman's rho) between the different aspects of drug use and the outcomes on the updating measures. The results are set out in Table 4. It is clear that only aspects of ecstasy use are significantly correlated with the updating executive component measures. None of the aspects of cocaine use are associated with statistically significant correlations.

$<$ Insert Table 4 about here $>$

\section{Discussion}

No significant ecstasy-related differences were observed in the random letter generation task. The consonants only version used here was the same as that used in our early research and as noted above this was associated with a significant group difference in our initial study (Wareing et al, 2000). Mean lifetime consumption of ecstasy tablets exceeded 1000 in that study which is appreciably higher than was apparent in our 
subsequent research. Furthermore there is clear evidence that restricting the letter set to consonants only, caused particular problems for the ecstasy users groups in Wareing et al's (2000) study as they produced significantly more vowel intrusions under all generation rates. Thus it had been conjectured that deficits might be found in the present study among heavy chronic users on the consonants only version of the task. However, the results presented here demonstrated that this was not the case. The basis for the significant group difference in our original study (Wareing et al, 2000) remains unclear. With just 10 participants in each group, the sample sizes were small. Furthermore in our previous study, we did not assess participants on measures of intelligence. Thus it remains possible that the differences we observed might have been due to some premorbid factor other than drug use. The fact that the present study along with other recent results from our laboratory (Fisk et al 2004; Montgomery et al 2005) have not revealed ecstasy related deficits in random letter generation suggest that this aspect of cognitive functioning is unimpaired. Since random letter generation is an established measure of the inhibition component executive process, it would seem reasonable to conclude that ecstasy use does not adversely affect this aspect of cognition.

Research from our own laboratory has suggested that ecstasy use may be associated with deficits in the updating executive component process. Two measures of the updating function appear to be subject to ecstasy-related impairment, computation span and letter updating (Montgomery et al, 2005). However, with regard to the latter, in our previous study, participants were required to maintain a load of six letters while concurrently performing the updating task. It appears that this load exceeded the letter span of the majority of participants and for these individuals it would have been 
impossible to perform the maintenance element of the task. This raises the question of whether any serial rehearsal element and concurrent updating activity was actually occurring. It is possible that participants may have adopted a free recall strategy with a reliance on the recency component of the process. Baddeley and Hitch (1993) have argued that the recency phenomenon is distinct from the maintenance and processing functions of working memory. Thus while we have demonstrated an ecstasy related deficit in letter updating, this may not in fact reflect an executive function deficit. In an important early study of the updating process Morris and Jones (1990) addressed this problem by running two experiments, the first with a load of six letters and the second with a load of four letters. However, reducing the load to four letters is not without problems as it makes it possible for those individuals with large letter spans to avoid updating all together by encoding and serially rehearsing the entire sequence where the presented sequence length allows this. In order to address this problem, in the present study participants were required to maintain a load that was equivalent to their letter span. The orthogonal difference contrasts revealed that following control for group differences in cannabis consumption ecstasy users performed worse than nonusers on all three measures of the updating component executive process, including the letter updating task, computation span, and visuo-spatial updating. Thus it can be argued with some degree of confidence that ecstasy users are impaired on this executive component function.

It has been argued that the storage aspects of the working memory system are domain specific while processing is domain-general in nature (e.g., Bayliss et al 2003; Kane et al , 2004). Thus verbal and visuo spatial information would be stored by functionally separate systems but the processing component of tasks utilising this 
information would be domain-general in nature. Given that ecstasy users have been found to exhibit deficits in verbal updating, the domain general nature of the process would imply that deficits should also be apparent in updating visuo-spatial information. In our previous research we have found ecstasy users to be impaired in a visuo-spatial complex span task (Wareing et al, 2004; 2005). While analogous verbal tasks have been found to load on the updating component executive process (Miyake et al, 2000; Fisk \& Sharp, 2004), it is unclear whether this applies to the visuo-spatial working memory task that we employed previously. The present study has used an analogue of the verbal updating task, in which individuals were required to maintain and update a spatial sequence and it was established that ecstasy users were significantly impaired on this task relative to nonusers. The presence of deficits on both the verbal and visuo-spatial updating tasks is consistent with Baylis et al (2003) and Kane et al's (2004) view of working memory and it may be that the deficits observed reflect an ecstasy-related impairment in this domain general updating process.

The present findings may be viewed in the context of recent neuroscience evidence. It is known that MDMA affects both serotonergic and dopaminergic systems (e.g. Kish et al, 2002). Functional neuroimaging studies indicating that ecstasy/polydrugrelated neurotransmitter changes may be concentrated in the dorsolateral and parietal regions of the prefrontal cortex (Cohen et al, 1996), and in addition may give rise to significantly lower grey matter concentrations in multiple brain regions (bilateral BA 18 and cerebellum, left BA 21 and left BA 45, as well as the midline brainstem; Cowan et al. 2003). Memory updating has been particularly linked to the dorsolateral prefrontal cortex (Goldman-Rakic, 1996) while performance on the letter-updating task is most strongly 
associated with the left fronto-polar cortex (Collette et al, 2006; Van-der-Linden et al, 1999). So it is likely that the deficits observed in the present study reflect reduced serotonergic/dopaminergic functioning in specific regions of the prefrontal cortex.

As with most studies in this area, a number of limitations need to be acknowledged. Due to the quasi-experimental design of the study, it is possible that the groups in each study may have differed on some variable other than ecstasy use. The groups differed significantly in age and although the tests administered are subject to agerelated decline, this does not typically occur until old age. None of the participants tested in the present study were more than 27 years old. Group differences in other variables such as general health, nutrition, or some premorbid condition predating drug use (Verheul, 2001) cannot be ruled out. Furthermore, due to limited resources we were unable to provide an objective measure of recent drug use (e.g. from hair or urine samples). However, most published studies testing cognitive deficits among ecstasy users have not used these techniques (e.g. Fox et al, 2002; Morgan, 1998; Rodgers, 2000). We were able to statistically control for group differences in both recent and longer term aspects of cannabis use. Furthermore, aspects of ecstasy use were more closely correlated with the cognitive outcomes compared to the equivalent correlations with cocaine use. However it must be acknowledged that a minority of the ecstasy users had in the past used amphetamine and a small number LSD. We cannot therefore entirely exclude the possibility that these drugs may have played some role in the results that were obtained. 


\section{References}

Baddeley AD (1966). The capacity for generating information by randomization. $Q J$ Exp Psychol 18: 119-129.

Baddeley AD, \& Hitch, GJ (1993). The recency effect: Implicit learning with explicit retrieval. Memory \& Cognition 21: 146-155.

Bayliss DM, Jarrold C, Gunn DM, \& Baddeley AD (2003). The complexities of complex span: Explaining individual differences in working memory in children and adults. J Exp Psychol Gen 132: 71-92.

Brooks LR (1967). The suppression of visualisation by reading. Q J Exp Psychol 19: 289-299.

Cohen Z, Bonvento G, Lacombe P, Hamel E (1996). Serotonin in the regulation of brain microcirculation. Prog Neurobiol 50: 335-362.

Collette F, Hogge M, Salmon E, \& M. Van der Linden, M (2006). Exploration of the neural substrates of executive functioning by functional neuroimaging. Neuroscience 139: 209-221.

Cowan RL, Lyoo IK, Sung SM, Ahn KH, Kim MJ, Hwang J, Haga E, Vimal RLP, Lukas SE, Renshaw PF (2003). Reduced cortical gray matter density in human MDMA (ecstasy) users: a voxel-based morphometry study. Drug Alcohol Depend 72: 225235.

Dafters RI (2006). Chronic ecstasy (MDMA) use is associated with deficits in, taskswitching but not inhibition or memory updating executive functions. Drug Alcohol Depend 83: 181-184. 
Fisk JE, Montgomery C, Murphy P, \& Wareing M (2004). Evidence of executive deficits among users of MDMA (Ecstasy). Br J Psychol 95: 457-466.

Fisk JE, \& Sharp CA (2003). The role of the executive system in visuo-spatial memory functioning. BrainCogn 52: 364-381.

Fisk JE, \& Sharp CA (2004). Age-related impairment in executive functioning: Updating, inhibition, shifting, and access. J Clin Exp Neuropsychol 26: 874-890

Fisk JE, Warr P (1996) Age and Working memory: the role of perceptual speed, the Central Executive and the phonological loop. Psychol Aging 11: 316-323

Fox HC, McLean A, Turner JJD, Parrott AC, Rogers R, Sahakian BJ (2002) Neuropsychological evidence of a relatively selective profile of temporal dysfunction in drug-free MDMA (“ecstasy”) polydrug users. Psychopharmacology 162: 203-214

Goldman-Rakic PS (1996) The prefrontal landscape: Implications of functional architecture for understanding human mentation and the central executive. Philos Trans R Soc Lond 351: 1445-1453

Gouzoulis-Mayfrank E, Daumann J (2006). Neurotoxicity of methylenedioxyamphetamines (MDMA; ecstasy) in humans: how strong is the evidence for persistent brain damage? Addiction 101:348-361.

Hinkle DE, Wiersma W, Jurs SG (1994) Applied Statistics for the Behavioral Sciences ( $3^{\text {rd }}$ ed.). Boston MA: Houghton Mifflin Company

Kane MJ, Hambrick DZ, Tuholski SW, Wilhelm O, Payne TW, \& Engle RW (2004). The generality of working-memory capacity: A latent-variable approach to verbal and visuo-spatial memory span and reasoning. J Exp Psychol Gen 133: 189-217. 
Kish SJ (2002) How strong is the evidence that brain serotonin neurons are damaged in human users of ecstasy? Pharmacol Biochem Behav 71: 845-855

Luciana M, Collins PF, Depue RA (1998). Opposing roles for dopamine and serotonin in the modulation of human spatial working memory functions. Cereb Cortex 8: 218-226.

Miyake A, Friedman NP, Emerson MJ, Witzki AH, Howerter A, Wager TD (2000) The unity and Diversity of executive functions, and their contributions to complex “frontal lobe” tasks: A latent variable analysis. Cognit Psychol 41: 49-100.

Montgomery C, Fisk JE, Newcombe R, \& Murphy PN (2005). The differential effects of ecstasy/polydrug use on executive components: Shifting, inhibition, updating and access to semantic memory. Psychopharmacology 182: 262-276.

Morgan MJ (1998) Recreational use of “ecstasy” (MDMA) is associated with elevated impulsivity. Neuropsychopharmacology 19: 252-264

Morgan MJ (2000) Ecstasy (MDMA): A review of its possible persistent psychological effects. Psychopharmacology 152: 230-248

Morris N, \& Jones DM (1990). Memory updating in working memory: The role of the central executive. Br J Psychol 81, 111-121.

Nelson HE (1982). National Adult Reading Test (NART) Test Manual. Windsor, Berkshire, UK: NFER-Nelson

Raven J, Raven JC, Court JH (1998). Manual for Raven’s Progressive Matrices and Vocabulary Scales. Oxford, UK: Oxford Psychologists Press 
Reneman L, Schilt T, de Win MM, Booij J, Schmand B, van den Brink W, Bakker O (2006). Memory function and serotonin transporter promoter gene polymorphism in ecstasy (MDMA) users. J Psychopharmacol 20: 389-399.

Robbins TW (2000). Chemical neuromodulation of frontal-executive functions in humans and other animals. Exp Brain Res 133: 130-138.

Rodgers J (2000). Cognitive performance amongst recreational users of “ecstasy”. Psychopharmacology 151: 19-24

Salthouse TA, Babcock RL (1991) Decomposing adult age differences in working memory. Dev Psychol 27: 763-776

Smith-Spark JH, \& Fisk JE (in press). Central executive functioning in developmental dyslexia. Memory.

Smith-Spark JH, Fisk JE, Fawcett AJ, \& Nicolson RI (2003). Investigating the central executive in adult dyslexics: Evidence from phonological and visuospatial working memory performance. European Journal of Cognitive Psychology 15: 567-587.

Solowij N, Hall W, Lee N (1992). Recreational MDMA use in Sydney: a profile of 'Ecstacy' users and their experiences with the drug. Br J Addict 87: 1161-72

Tabachnick, B. G., \& Fidell, L. S. (2001). Using Multivariate Statistics, (4 $4^{\text {th }}$ Ed.). Boston, MA, USA: Allyn and Bacon.

Van der Linden M, Collette F, Salmon E, Delfiore G, Delgueldre C, Luxen A, Franck G (1999). The neural correlates of updating information in verbal working memory. Memory 7: 549-560.

Verheul R (2001). Co-morbidity of personality disorders in individuals with substance 
use disorders. Eur Psychiatry 16: 274-282

Wareing M, Fisk JE, \& Murphy PN (2000). Working memory deficits in current and previous users of MDMA (“Ecstasy”). Br J Psychol 91: 181-188.

Wareing M, Fisk JE, Murphy P, \& Montgomery C (2005). Visuo-spatial working memory deficits in current and former users of MDMA ('Ecstasy’). Hum Psychopharmacol 20: 115-123.

Wareing M, Fisk JE, Murphy P, \& Montgomery C (2004). Verbal working memory deficits in current and previous users of MDMA. Hum Psychopharmacol 19: 225234.

Wareing M, Fisk JE, Murphy P, \& Montgomery C (2005). Visuo-spatial working memory deficits in current and former users of MDMA ('Ecstasy’). Hum Psychopharmacol 20: 115-123.

Wareing M, Murphy P, \& Fisk JE (2004). Visuospatial memory impairments in users of MDMA ('ecstasy'). Psychopharmacology 173: 391-397. 
John E Fisk

Table 1: Background Variables

\begin{tabular}{|c|c|c|c|c|c|c|c|}
\hline & \multicolumn{2}{|c|}{$\begin{array}{c}\text { Heavy Ecstasy } \\
\text { users }\end{array}$} & \multicolumn{2}{|c|}{$\begin{array}{l}\text { Light Ecstasy } \\
\text { Users }\end{array}$} & \multicolumn{2}{|c|}{$\begin{array}{c}\text { Non Ecstasy } \\
\text { Users }\end{array}$} & \multirow[t]{2}{*}{$\mathrm{F}(2,78)$} \\
\hline & Mean & S.D. & Mean & S.D. & Mean & S.D. & \\
\hline Age (years) & 22.86 & 2.38 & 21.41 & 2.05 & 20.71 & 1.37 & $5.91 * *$ \\
\hline Years of Education & 15.11 & 2.66 & 14.87 & 3.11 & 15.55 & 2.24 & $<1$ \\
\hline $\begin{array}{l}\text { Raven's } \\
\text { Progressive } \\
\text { Matrices (maximum } \\
60 \text { ) }\end{array}$ & 45.86 & 7.19 & 46.74 & 5.96 & 49.36 & 5.06 & 2.25 \\
\hline $\begin{array}{l}\text { NART (maximum } \\
50 \text { ) }\end{array}$ & 27.86 & 8.39 & 28.72 & 5.67 & 29.14 & 5.02 & $<1$ \\
\hline Digit Span & 6.86 & 1.03 & 6.89 & 1.17 & 6.60 & 1.47 & $<1$ \\
\hline Letter Span & 5.21 & 1.05 & 5.46 & 0.94 & 5.04 & 0.84 & 1.75 \\
\hline Spatial Span & 4.57 & 0.85 & 4.92 & 0.77 & 4.57 & 0.96 & 1.71 \\
\hline
\end{tabular}


Table 2: Indicators of Illicit Drug Use

\begin{tabular}{|c|c|c|c|c|c|c|c|c|c|c|c|c|}
\hline & \multicolumn{4}{|c|}{ Heavy Ecstasy Users } & \multicolumn{4}{|c|}{ Light Ecstasy Users } & \multicolumn{4}{|c|}{ Non Ecstasy Users } \\
\hline & Median & Mean & S.D. & $\mathrm{n}$ & Median & Mean & S.D. & $\mathrm{n}$ & Median & Mean & S.D. & $\mathrm{n}$ \\
\hline \multicolumn{13}{|l|}{ Total Use } \\
\hline Ecstasy (Tablets) & 6.8 .00 & 1000.21 & 786.41 & 14 & 142.00 & 149.69 & 96.91 & 39 & 0.00 & 0.00 & 0.00 & 28 \\
\hline Cannabis (joints) & 5200.00 & 6383.27 & 5830.32 & 11 & 320.00 & 1779.51 & 2971.07 & 37 & 22.00 & 262.13 & 507.44 & 23 \\
\hline Cocaine (grams) & 75.75 & 127.52 & 144.64 & 6 & 0.00 & 17.51 & 35.84 & 21 & 0.00 & 0.00 & 0.00 & 25 \\
\hline \multicolumn{13}{|c|}{ Average Weekly Dose } \\
\hline Ecstasy (tablets) & 2.87 & 3.49 & 2.05 & 14 & 0.73 & 0.99 & 0.68 & 38 & 0.00 & 0.00 & 0.00 & 28 \\
\hline Cannabis (joints) & 15.08 & 15.59 & 12.76 & 11 & 2.40 & 5.96 & 9.97 & 35 & 0.17 & 1.60 & 2.84 & 23 \\
\hline Cocaine (grams) & 0.44 & 0.52 & 0.47 & 6 & 0.00 & 0.14 & 0.29 & 21 & 0.00 & 0.00 & 0.00 & 25 \\
\hline \multicolumn{13}{|c|}{ Length of use (weeks) } \\
\hline Ecstasy & 271.00 & 300.82 & 136.12 & 14 & 148.00 & 176.29 & 108.55 & 39 & - & - & - & - \\
\hline Cannabis & 260.00 & 342.14 & 184.14 & 13 & 268.00 & 283.56 & 145.16 & 33 & 172.00 & 172.83 & 106.63 & 21 \\
\hline Cocaine & 217.22 & 240.63 & 136.35 & 14 & 121.00 & 137.65 & 79.50 & 27 & - & - & - & - \\
\hline \multirow{2}{*}{\multicolumn{13}{|c|}{$\begin{array}{l}\text { Drugs Used During the } \\
30 \text { days Prior to Testing }\end{array}$}} \\
\hline & & & & & & & & & & & & \\
\hline Ecstasy & 0.00 & 2.61 & 4.09 & 14 & 0.50 & 1.73 & 2.60 & 39 & 0.00 & 0.00 & 0.00 & 28 \\
\hline Cannabis & 24.00 & 56.31 & 75.15 & 13 & 3.00 & 22.80 & 45.00 & 38 & 0.00 & 7.04 & 29.30 & 26 \\
\hline Cocaine & 0.25 & 0.45 & 0.55 & 10 & 0.00 & 0.25 & 0.66 & 30 & 0.00 & 0.00 & 0.00 & 27 \\
\hline \multicolumn{13}{|c|}{ Drugs Used During the } \\
\hline \multicolumn{13}{|c|}{10 days Prior to Testing } \\
\hline Ecstasy & 0.00 & 0.68 & 1.49 & 14 & 0.00 & 0.32 & 0.86 & 39 & 0.00 & 0.00 & 0.00 & 28 \\
\hline Cannabis & 0.50 & 6.75 & 12.50 & 14 & 0.00 & 2.79 & 6.03 & 39 & 0.00 & 1.14 & 3.57 & 28 \\
\hline Cocaine & 0.00 & 0.10 & 0.18 & 14 & 0.00 & 0.08 & 0.24 & 39 & 0.00 & 0.00 & 0.00 & 28 \\
\hline
\end{tabular}


Table 2 continued

$\begin{array}{cc}\text { Overall Group Effect: Kruskal- } & \text { Heavy Ecstasy Users versus Light } \\ \text { Wallace }(\chi) & \text { Users: Mann-Whitney U value }\end{array}$

\begin{tabular}{llc}
\hline Total Use & & \\
Ecstasy (Tablets) & $\chi(\mathrm{df}=2, \mathrm{~N}=81)=70.26^{* * *}$ & $0.00^{* * *}$ \\
Cannabis (joints) & $\chi(\mathrm{df}=2, \mathrm{~N}=71)=16.65^{* * *}$ & $113.50^{*}$ \\
$\begin{array}{l}\text { Cocaine (grams) } \\
\text { Average Weekly Dose }\end{array}$ & $\chi(\mathrm{df}=2, \mathrm{~N}=52)=28.37^{* * *}$ & $16.50^{* *}$ \\
$\quad$ & \\
Ecstasy (tablets) & $\chi(\mathrm{df}=2, \mathrm{~N}=80)=65.49^{* * *}$ & $46.00^{* * *}$ \\
Cannabis (joints) & $\chi(\mathrm{df}=2, \mathrm{~N}=69)=13.37^{* *}$ & $108.50^{*}$ \\
Cocaine (grams) & $\chi(\mathrm{df}=2, \mathrm{~N}=52)=27.43^{* * *}$ & $21.00^{*}$ \\
Length of use (weeks) & & \\
Ecstasy & $\chi(\mathrm{df}=2, \mathrm{~N}=67)=10.29^{* *}$ & $115.50^{* *}$ \\
Cannabis & & 178.50 \\
Cocaine & & $91.00^{* *}$ \\
Drugs Used During the & & \\
30 days Prior to Testing & & \\
Ecstasy & $\chi(\mathrm{df}=2, \mathrm{~N}=81)=19.07^{* * *}$ & 272.00 \\
Cannabis & $\chi(\mathrm{df}=2, \mathrm{~N}=77)=9.77^{* *}$ & 109.50 \\
Cocaine & $\chi(\mathrm{df}=2, \mathrm{~N}=67)=13.65^{* *}$ & \\
Drugs Used During the & & \\
10 days Prior to Testing & & 251.50 \\
Ecstasy & $\chi(\mathrm{df}=2, \mathrm{~N}=81)=5.80$ & 235.00 \\
Cannabis & $\chi(\mathrm{df}=2, \mathrm{~N}=81)=6.25^{*}$ & 246.00 \\
Cocaine & $\chi(\mathrm{df}=2, \mathrm{~N}=81)=7.48^{*}$ & \\
\hline
\end{tabular}


Table 3 Performance on Executive Measures

\begin{tabular}{|c|c|c|c|c|c|c|}
\hline & \multicolumn{2}{|c|}{$\begin{array}{l}\text { Heavy Ecstasy } \\
\text { users }\end{array}$} & \multicolumn{2}{|c|}{$\begin{array}{l}\text { Light Ecstasy } \\
\text { Users }\end{array}$} & \multicolumn{2}{|c|}{$\begin{array}{l}\text { Non Ecstasy } \\
\text { Users }\end{array}$} \\
\hline & Mean & S.D. & Mean & S.D. & Mean & S.D. \\
\hline \multicolumn{7}{|l|}{ Random Generation } \\
\hline \multicolumn{7}{|l|}{ Redundancy } \\
\hline 4 second & 4.78 & 2.53 & 4.00 & 1.72 & 4.49 & 2.14 \\
\hline 2 second & 5.95 & 1.94 & 5.01 & 2.05 & 5.11 & 2.26 \\
\hline 1 second & 7.05 & 3.00 & 7.17 & 3.02 & 7.37 & 2.15 \\
\hline \multicolumn{7}{|l|}{ Repeat Sequences } \\
\hline 4 second & 16.00 & 3.26 & 14.05 & 4.76 & 14.14 & 4.28 \\
\hline 2 second & 16.86 & 3.61 & 16.72 & 6.41 & 16.54 & 4.77 \\
\hline 1 second & 19.07 & 8.40 & 18.23 & 5.89 & 18.39 & 6.15 \\
\hline \multicolumn{7}{|l|}{ Alphabetic Sequences } \\
\hline 4 second & 5.07 & 2.50 & 4.62 & 3.88 & 3.79 & 3.37 \\
\hline 2 second & 6.79 & 3.58 & 7.10 & 5.08 & 6.96 & 4.62 \\
\hline 1 second & 10.86 & 5.55 & 11.87 & 6.51 & 12.11 & 6.44 \\
\hline \multicolumn{7}{|l|}{ Vowel Intrusions } \\
\hline 4 second & 0.71 & 0.83 & 1.23 & 1.86 & 1.18 & 1.49 \\
\hline 2 second & 1.29 & 1.49 & 1.49 & 2.76 & 1.61 & 2.06 \\
\hline 1 second & 2.79 & 3.02 & 3.18 & 3.43 & 3.04 & 2.25 \\
\hline \multicolumn{7}{|c|}{ Number of Letters Generated } \\
\hline 4 second & 100.14 & 0.36 & 100.15 & 0.43 & 100.11 & 0.50 \\
\hline 2 second & 99.93 & 1.00 & 99.15 & 3.08 & 98.79 & 3.08 \\
\hline 1 second & 90.00 & 11.73 & 89.74 & 9.51 & 88.43 & 10.15 \\
\hline $\begin{array}{l}\text { Computation Span (\% } \\
\text { cost) }\end{array}$ & 49.04 & 28.75 & 41.32 & 25.21 & 29.43 & 23.00 \\
\hline Consonant Updating & 3.99 & 0.71 & 3.83 & 0.83 & 4.22 & 0.61 \\
\hline Spatial Updating & 4.01 & 0.56 & 4.03 & 0.66 & 4.48 & 0.75 \\
\hline
\end{tabular}


Table 4. Correlations between Aspects of Illicit Drug Use and Updating Executive Component Measures

\begin{tabular}{|c|c|c|c|c|}
\hline & $\begin{array}{r}\text { Computation } \\
\text { Span } \\
\end{array}$ & $\begin{array}{r}\text { Verbal } \\
\text { Updating }\end{array}$ & $\begin{array}{r}\text { Spatial } \\
\text { Updating } \\
\end{array}$ & $\mathrm{n}$ \\
\hline \multicolumn{5}{|l|}{ Total Use } \\
\hline Ecstasy (Tablets) & $.295 * *$ & $-.234 *$ & $-.235^{*}$ & 80 \\
\hline \multicolumn{5}{|l|}{ Amphetamine } \\
\hline Cannabis (joints) & .040 & .035 & -.020 & 70 \\
\hline Cocaine (grams) & .246 & .014 & -.183 & 51 \\
\hline \multicolumn{5}{|c|}{ Average Weekly Dose } \\
\hline Ecstasy (tablets) & $.316^{* *}$ & $-.279 *$ & $-.288 * *$ & 79 \\
\hline \multicolumn{5}{|l|}{ Amphetamine } \\
\hline Cannabis (joints) & .011 & .036 & -.020 & 68 \\
\hline Cocaine (grams) & .251 & .013 & -.188 & 51 \\
\hline \multicolumn{5}{|c|}{ Length of use (weeks) } \\
\hline Ecstasy & .075 & .147 & .081 & 53 \\
\hline \multicolumn{5}{|l|}{ Amphetamine } \\
\hline Cannabis & -.121 & -.127 & -.031 & 43 \\
\hline Cocaine & .183 & .079 & -.017 & 66 \\
\hline \multicolumn{5}{|c|}{ Drugs Used During the 30 days Prior to } \\
\hline \multicolumn{5}{|l|}{ Testing } \\
\hline Ecstasy & .117 & -.125 & $-.305 * *$ & 80 \\
\hline \multicolumn{5}{|l|}{ Amphetamine } \\
\hline Cannabis & .106 & .039 & -.055 & 76 \\
\hline Cocaine & .024 & .069 & -.166 & 66 \\
\hline \multicolumn{5}{|c|}{ Drugs Used During the 10 days Prior to } \\
\hline \multicolumn{5}{|c|}{ Testing } \\
\hline Ecstasy & -.084 & .008 & .036 & 80 \\
\hline \multicolumn{5}{|l|}{ Amphetamine } \\
\hline Cannabis & .123 & -.093 & -.194 & 80 \\
\hline Cocaine & .032 & .009 & -.169 & 80 \\
\hline
\end{tabular}

